\title{
Multitrophic Interactions Between Arbuscular Mycorrhizal Fungi, Foliar Endophytic Fungi and Aphids
}

\author{
Nadia Ab Razak ${ }^{1}$ (i) $\cdot$ Alan C. Gange ${ }^{1}$ (i)
}

Received: 8 September 2021 / Accepted: 2 December 2021 / Published online: 13 December 2021

(c) The Author(s) 2021

\begin{abstract}
Almost all living plants can be simultaneously colonised by arbuscular mycorrhizal fungi in the roots and endophytes in the shoots, while also being attacked by insect herbivores. However, to date, no study has ever examined the multitrophic interactions between these two different fungal groups and insects on any species of forb. Here, we examined the effects of two commercial species mixtures of arbuscular mycorrhizal fungi (AMF) and two foliar endophytes (Colletotrichum acutatum and Cladosporium oxysporum) on the growth of an invasive weed, Impatiens glandulifera, and the aphids that attack it. AMF reduced plant biomass, which was most evident when $C$. oxysporum was inoculated. Mycorrhizal fungi had few effects on aphids, and these depended on the identity of the endophytes present. Meanwhile, endophytes tended to increase aphid numbers, but this depended on the identity of the AMF inoculum. Throughout, there were differences in the responses of the plant to the two mycorrhizal mixtures, demonstrating clear AMF specificity in this plant. These specific effects were also strongly affected by the endophytes, with a greater number of interactions found between the AMF and endophytes than between the endophytes themselves. In particular, AMF reduced infection levels by the endophytes, while some endophyte inoculations reduced mycorrhizal colonisation. We suggest that both AMF and endophytes could play an important part in future biological control programmes of weeds, but further multitrophic experiments are required to unravel the complexity of interactions between spatially separated parts of the plant microbiome.
\end{abstract}

Keywords Arbuscular mycorrhiza $\cdot$ Endophyte $\cdot$ Impatiens glandulifera $\cdot$ Inoculant $\cdot$ Insect

\section{Introduction}

Ever since the assertion that plants are not discrete entities, but instead harbour a considerable diversity of fungi within their tissues [1], ecologists have studied the pairwise interactions between these fungi and their hosts. However, the microbial community within plants, collectively known as the microbiome, is complex and contains an array of bacterial species, along with beneficial fungal symbionts in the roots (e.g. mycorrhizal fungi or dark septate endophytes), and other fungi in the shoots (e.g. endophytes, pathogens and other species that appear to be benign) $[2,3]$. Despite various reviews lamenting the lack of multitrophic

Alan C. Gange

a.gange@rhul.ac.uk

Nadia Ab Razak

nadiarazak89@yahoo.com

1 Department of Biological Sciences, Royal Holloway University of London, Egham TW20 0EX, Surrey, UK experiments involving the interactions between plants, their associated fungi and other trophic levels such as herbivores $[4,5]$, there is still a notable lack of studies that go beyond pairwise combinations to involve multiple microbial and/or herbivore species.

With the exception of plant pathogens, the most wellstudied parts of the microbiome are Clavicipitaceous endophytes in grasses and the arbuscular mycorrhizal fungi (AMF) [4]. Pairwise interactions between these groups have often focused on the Poaceae, due to the agronomic and economic importance of this group. These studies have reported a wide variety of outcomes across many grass hosts, in which the fungi affect each other positively or negatively, with differing consequences for the host plant [6-8]. Such context-dependent results can be influenced by variation in abiotic factors, as well as the identity of the fungi and the plants concerned [9]. However, these interactions are important, as they propagate up food chains to affect insect herbivores. For example, colonisation of Lolium perenne by AMF tended to reduce the antagonistic effects of foliar 
fungal endophyte infection on larvae of the generalist moth Phlogophora meticulosa [10].

In contrast to grasses, microbial ecology studies in forbs (i.e. herbaceous plants that are not grasses, sedges or rushes) tend to be dominated by those involving AMF [4]. This is not surprising, given that up to $80 \%$ of forbs form an arbuscular mycorrhiza, with many important crop plants showing growth benefits when colonised by these fungi [11]. What is more surprising is that forbs also host a huge diversity of endophytic fungi in their roots and shoots [12, 13], yet nothing is known about the interactions of these fungi with their hosts, AMF and insects. These unspecialised endophytes in forbs comprise saprotrophs, latent pathogens, pathogens of other hosts (recently termed 'schizotrophism' [14]) and entomopathogenic fungi $[12,15]$. Although the occurrence of these fungi in foliar tissues is often localised [16], they form a dynamic community, increasing plant resistance to insect herbivores and pathogens $[17,18]$, while having positive or negative effects on AMF, but often being antagonistic towards each other [19-21]. These endophytes therefore seem to be mainly beneficial to their hosts [15].

Arbuscular mycorrhizal fungi are also largely beneficial to their hosts, by increasing the nutrient supply and enhancing host plant resistance to some pests and pathogens [22]. However, it is widely recognised that ecological specificity exists in the mycorrhizal symbiosis [23], wherein the outcome of the interaction between fungi and the host is dependent on the identity of each, soil and environmental conditions, and the presence of other organisms, such as herbivores [24]. In certain conditions, AMF can lead to growth depressions in plants [25] while they frequently increase the growth and reproduction of sucking insect pests, such as aphids [26, 27]. From the commercial point of view, such detrimental effects on plants would not be a desirable feature of the mycorrhizal symbiosis, but one potential application occurs with the biological control of weeds [28]. Many annual weed species seem to be facultatively mycorrhizal at best and can show decreased growth, either as a direct effect of mycorrhizal colonisation, or from increased competition, due to neighbouring plants responding strongly to the presence of the fungi [28].

One invasive annual weed that seems to derive little benefit from AMF is Himalayan balsam, Impatiens glandulifera. Introduced from northern India and Pakistan in 1839, this plant is now regarded as one of the most invasive weeds in the UK and throughout Europe [29]. Studies have shown that the plant is antagonised by AM fungi in the introduced range and that it is able to reduce populations of indigenous fungi in the soil to its own advantage but to the detriment of native plant species [30-32]. This plant has been the subject of a biological control programme in Great Britain, where the host-specific rust fungus Puccinia komarovii var. glanduliferae was first released in 2014 [33]. Success of the pathogen has been patchy, due to variable biotype resistance in the weed and the presence of endophyte fungi, some of which are antagonistic towards the rust $[34,35]$.

Invasive species represent important 'model systems' in which to investigate plant-microbe-insect interactions, where there is a continuous search for control methods not involving chemicals or manual labour [36]. Here, we report on a study designed to investigate whether AMF and two endophyte fungi (Colletotrichum acutatum and Cladosporium oxysporum) interact to affect the growth of this weed and whether fungal presence has any effect on populations of two aphid species that naturally attack balsam, Aphis fabae and Myzus ornatus. This was part of a larger project examining the factors affecting, and consequences of, biological control of this weed [37]. As I. glandulifera seems to be antagonised by AMF species that do not occur in its native range, we hypothesise that using commercial mixedspecies inoculants will reduce its growth. If so, this might then be exploited as a further biological control method for this weed. Our second hypothesis is that adding AMF will make the plant more susceptible to aphids, which could be problematic, as both aphids are pest species in the UK. However, as endophytes can be antagonistic to aphids, our third hypothesis is that endophyte presence might mitigate any mycorrhizal effect but that this might be further influenced by interactions amongst the endophytes themselves [17, 19, $26,31]$. To our knowledge, this is the first study to examine the interactions between various combinations of AM fungi, endophytes and insects in a non-grass host plant.

\section{Materials and Methods}

\section{Plant and Fungal Material}

Ripe I. glandulifera seeds were collected from wild populations at Harmondsworth Moor, Middlesex, UK $\left(51.48^{\circ} \mathrm{N},-0.48^{\circ} \mathrm{W}\right)$ in autumn and stored overwinter at $4{ }^{\circ} \mathrm{C}$ for 6 months to break dormancy. Seeds were surfacesterilised and germinated on moist filter paper in sterilised Petri dishes at $4{ }^{\circ} \mathrm{C}$.

In previous studies $[34,38]$, the two commonest endophytes isolated from I. glandulifera were Colletotrichum acutatum and Cladosporium oxysporum. The material was subjected to a molecular analysis for identification (described in full in ref. [34]) and deposited in GenBank with accession numbers MH428675 and MH428677, respectively, as well as the CABI culture collection (accession numbers IMI505519 and IMI505553, respectively). The material used here was from the same cultures studied by Currie et al. [34].

Two commercial mycorrhizal inoculants were used, provided by PlantWorks (Sittingbourne, Kent, UK) and 
Symbio (Wormley, Surrey, UK). The former (marketed as 'Rootgrow') contained Claroideoglomus claroideum, Funneliformis geosporus, F. mosseae, Glomus microaggregatum and Rhizophagus irregularis, while the latter (marketed as 'Granular mycorrhizae') contained Claroideoglomus etunicatum, Funneliformis mosseae, Gigaspora margarita, Glomus deserticola, Gl. monosporus, Rhizophagus aggregatus, $R$. clarum and R. irregularis. Hereafter, we refer to these two inoculants as 'PlantWorks' and 'Symbio' respectively.

\section{Experimental Design and Measurements}

There were eight treatments for each mycorrhizal inoculant, consisting of with and without AMF, with and without $C$. acutatum infection and with and without $C$. oxysporum, with five replicates of each. One germinated seedling was planted into a $2-\mathrm{L}$ pot, lined with a $38-\mu \mathrm{m}$ membrane and containing John Innes number 3 compost (Westland Horticulture, Huntingdon). At planting time, $15 \mathrm{~g}$ of PlantWorks or $2 \mathrm{~g}$ of Symbio inoculum was added to the planting hole, following the recommended rates for horticultural crops. As the inocula differed in mycorrhizal species and carrier material, we sterilised each at $120^{\circ} \mathrm{C}$ in an autoclave for $30 \mathrm{~min}$. Thus, there was a different control of sterilised material for each inoculum type and so the two parts of the experiment were analysed separately (see Statistical Analysis, below). In addition, each control received a $15-\mathrm{mL}$ microbial filtrate of live inoculum, in sterile water, passed through a $38-\mu \mathrm{m}$ membrane, to remove all mycorrhizal propagules [39]. Inoculation with endophytes was identical to that by Currie et al. [34], when plants were at the three-leaf whorl stage, they were sprayed with an inoculum containing approximately $1.5 \times 10^{5}$ spores $\mathrm{mL}^{-1}$ of $C$. acutatum and/or C. oxysporum in $0.05 \%$ Tween 80 . Leaves were sprayed on the abaxial surface and control plants received equal volumes of $0.05 \%$ Tween 80 only.

Pots were sunk into field soil and arranged in a randomised block design. Each pot was rotated weekly, to prevent the ingress of AMF hyphae from the surrounding soil [40] and given $250 \mathrm{~mL}$ water daily. Plants were grown for 11 weeks, when flower buds had formed. Harvesting then took place, as the terms of the license (from the Animal and Plant Health Agency) for growing this invasive species do not permit flowering and escape of seeds into the wild.

Plants became naturally colonised by two species of aphid, A. fabae and M. ornatus, and total numbers of each species on each plant were counted prior to vegetation removal. Plant height and fresh shoot biomass were recorded, and a sub-sample of roots and leaves was taken for quantification of mycorrhizal colonisation and endophyte infection.

Roots were stained with the ink and vinegar method [41] involving immersion in $10 \% \mathrm{KOH}$ at $80{ }^{\circ} \mathrm{C}$ for $25 \mathrm{~min}$, thorough rinsing in water and subsequent immersion in staining solution (84.4:15:0.6, distilled water: $1 \%$ hydrochloric acid: Quink blue ink) for $30 \mathrm{~min}$. Percent root length colonised by arbuscules was quantified with the cross-hair eye piece method [42], at $\times 200$ magnification, with 100 views recorded for each slide of root pieces.

To examine infection levels by the inoculated endophytes, as well as infection by other species (background infection), five intact (i.e. showing no signs of herbivore attack) and asymptomatic (showing no signs of disease) leaves were randomly picked from each plant. Endophyte fungi were isolated from three 6-mm discs taken from each leaf, in an identical manner to that described by Currie et al. [34]. Briefly, surface-sterilised discs were plated onto potato dextrose agar (PDA) and individual colonies subcultured onto potato carrot agar (PCA). Sporulating cultures on PCA were identified by Dr B. C. Sutton, while sterile cultures were subjected to molecular identification, as described in Currie et al. [34].

\section{Statistical Analysis}

Plant height and fresh biomass data were tested for normality and plots of residuals were examined. Biomass data were subjected to the logarithmic transformation, prior to analysis. As described above, the two parts of the experiment, involving the two mycorrhizal inocula, were analysed separately. Effects of mycorrhizal addition and that of the two endophytes were examined with three-factor analysis of variance. Aphid numbers and the number of background endophytes (i.e. non-inoculated species) per plant were analysed with a Poisson generalised linear model structure, using a log link function, having checked for overdispersion and employing mycorrhizal addition, and the two endophytes as main effects. Differences in percent root length colonised by mycorrhizal fungi were examined with analysis of variance, following the logit transformation [43], employing each endophyte as the main effect. The isolation frequency of each fungal endophyte species was calculated by dividing the total number of isolations (individual colonies) of each species in a plant by the total number of all fungal isolations for that plant [19]. Differences in isolation frequency were examined using a generalised linear model with a binomial error structure, after checking for overdispersion, and employing mycorrhizal addition and the two inoculated endophytes as main effects. All analyses were performed in R 4.0.2 [44].

\section{Results}

All significant terms (main effects and interactions) are described below, and summaries of all statistical results are presented in Tables 1 and 2. 
Table 1 Summary of the significant effects of, and interactions between PlantWorks inoculum (AM), inoculation with Colletotrichum acutatum (C.a.) and Cladosporium oxysporum (C.o.) on height and shoot biomass of I. glandulifera, total numbers of the aphids Aphis fabae and Myzus ornatus, arbuscular mycorrhizal colonisa- tion (AMF) and isolation frequency of C. acutatum and C. oxysporum. For the main effects, $\uparrow$ represents an increase in the parameter, while $\downarrow$ represents a decrease. Significance is indicated by $* P<0.05$, $* * P<0.01, * * * P<0.001$

\begin{tabular}{|c|c|c|c|c|c|c|c|}
\hline & Height & Biomass & A. fabae & M. ornatus & AMF & C. acutatum & C. oxysporum \\
\hline $\mathrm{AM}$ & - & $* \downarrow$ & $* * \uparrow$ & - & & $* \downarrow$ & - \\
\hline C.a & - & - & - & $* * \uparrow$ & $* * * \downarrow$ & $* * \uparrow$ & - \\
\hline C.o & $* * * \downarrow$ & $* \downarrow$ & - & $* * \uparrow$ & - & - & $* \uparrow$ \\
\hline AM x C.a & - & - & - & - & - & - & - \\
\hline AM x C.o & - & - & $\begin{array}{l}* * \text { AM effect } \\
\text { only with C.o }\end{array}$ & $\begin{array}{l}* \text { AM negates } \\
\text { effect of C.o }\end{array}$ & - & - & $\begin{array}{l}\text { * AM negates } \\
\text { effect of } \\
\text { C.o }\end{array}$ \\
\hline Ca. x C.o & - & $\begin{array}{l}\text { ** C.a. negates } \\
\text { effect of C.o }\end{array}$ & - & - & $\begin{array}{c}* * * \text { C.o. negates } \\
\text { effect of C.a }\end{array}$ & - & - \\
\hline AM x C.a. x C.o & $\begin{array}{l}* \text { C.a. negates effect } \\
\text { of AM and C.o }\end{array}$ & - & - & - & - & - & - \\
\hline
\end{tabular}

Table 2 Summary of the significant effects of, and interactions between Symbio inoculum (AM), inoculation with Colletotrichum acutatum (C.a.) and Cladosporium oxysporum (C.o.) on height and shoot biomass of I. glandulifera, total numbers of the aphids Aphis fabae and Myzus ornatus, arbuscular mycorrhizal colonisation (AMF) and isolation frequency of $C$. acutatum and $C$. oxysporum. For the main effects, $\uparrow$ represents an increase in the parameter, while $\downarrow$ represents a decrease. Significance is indicated by $* P<0.05$, ** $P<0.01$, $* * * P<0.001$

\begin{tabular}{|c|c|c|c|c|c|c|c|}
\hline & Height & Biomass & A. fabae & M. ornatus & $\mathrm{AMF}$ & C. acutatum & C. oxysporum \\
\hline $\mathrm{AM}$ & - & $* * \downarrow$ & - & - & & - & - \\
\hline C.a & - & - & - & - & - & $* * * \uparrow$ & - \\
\hline C.o & $* * * \downarrow$ & $* * * \downarrow$ & - & - & $* * \downarrow$ & - & $* * \uparrow$ \\
\hline AM x C.a & - & - & - & - & - & *AM enhances effect of C.a & - \\
\hline AM x C.o & - & - & - & - & - & $* *$ C.o. negates effect of AM & $\begin{array}{l}\text { * AM negates } \\
\text { effect of } \\
\text { C.o }\end{array}$ \\
\hline Ca. x C.o & - & - & - & - & - & - & - \\
\hline AM x C.a. x C.o & - & - & $\begin{array}{l}* \text { AM effect only } \\
\text { with no C.a. \& C.o }\end{array}$ & - & - & - & - \\
\hline
\end{tabular}

\section{Plant Growth Attributes}

Overall, addition of PlantWorks mycorrhizal inoculum had no effect on plant height; however, plants infected with $C$. oxysporum in this part of the experiment were shorter (main effect: $F_{1,32}=38.21, P<0.001$, Fig. 1a). When this endophyte was present, mycorrhizal fungi appeared to reduce height still further, producing the shortest plants. However, this effect was not seen if $C$. acutatum was present also, leading to a three-way interaction between the fungi $\left(F_{1,32}=6.64, P<0.05\right)$. An identical result was found with the Symbio inoculum, wherein $C$. oxysporum reduced plant height (main effect: $F_{1,32}=26.93, P<0.001$ ), though no interactions between the fungi were found (Fig. 1b).

Overall, there was a $13 \%$ reduction in plant biomass from inoculation with PlantWorks mycorrhizal fungi, showing a weak statistical difference $(P=0.057)$. However, the reduction in height caused by inoculation with C. oxysporum also translated into a large reduction in biomass (main effect: $F_{1,32}=27.08, P<0.001$, Fig. $2 \mathrm{a}$ ). In this case, there was a significant interaction between the two endophytes $\left(F_{1,32}=8.32, P<0.01\right)$; if $C$. acutatum was not inoculated, $C$. oxysporum reduced biomass by $46 \%$, but when $C$. acutatum was also inoculated, the reduction by C. oxysporum was only $18 \%$ (Fig. 2 a). Meanwhile, addition of the Symbio inoculum significantly reduced fresh biomass, irrespective of whether the endophytes were also inoculated (main effect: $F_{1,32}=10.89, P<0.01$, Fig. $2 b$ ). Inoculation of $C$. oxysporum again reduced plant biomass by $43 \%$ overall (main effect: $F_{1,32}=39.33, P<0.001$ ), with the smallest plants being those inoculated with this endophyte and the mycorrhizal fungi (Fig. 2b, Tables 1 and 2). 

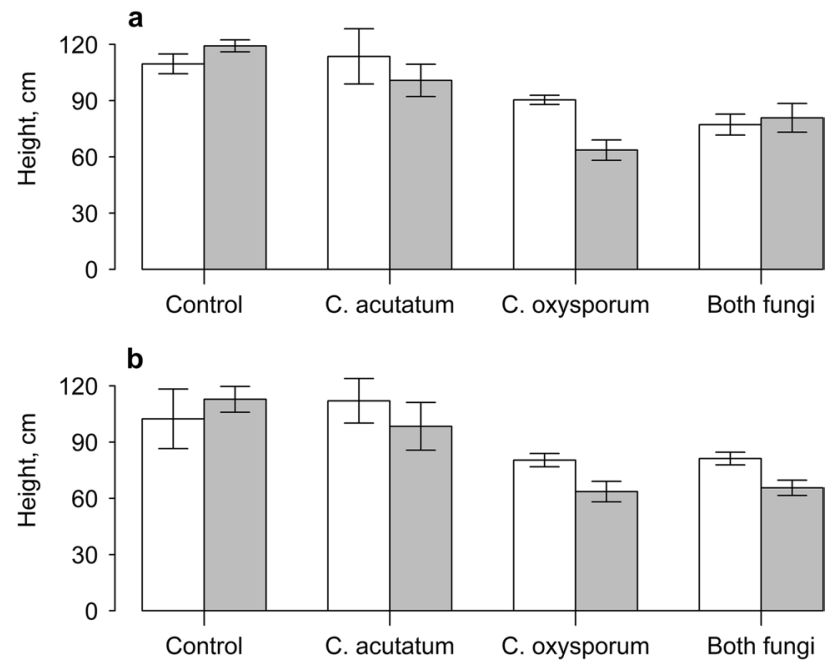

Fig. 1 Height of Himalayan balsam plants grown with addition of PlantWorks mycorrhizal inoculum (a) or Symbio mycorrhizal inoculum (b). White bars indicate sterilised inoculum, grey bars indicate live mycorrhizal fungi. Plants were also inoculated with no endophytes (control), Colletotrichum acutatum, Cladosporium oxysporum or both endophyte fungi. Vertical bars represent \pm one standard error
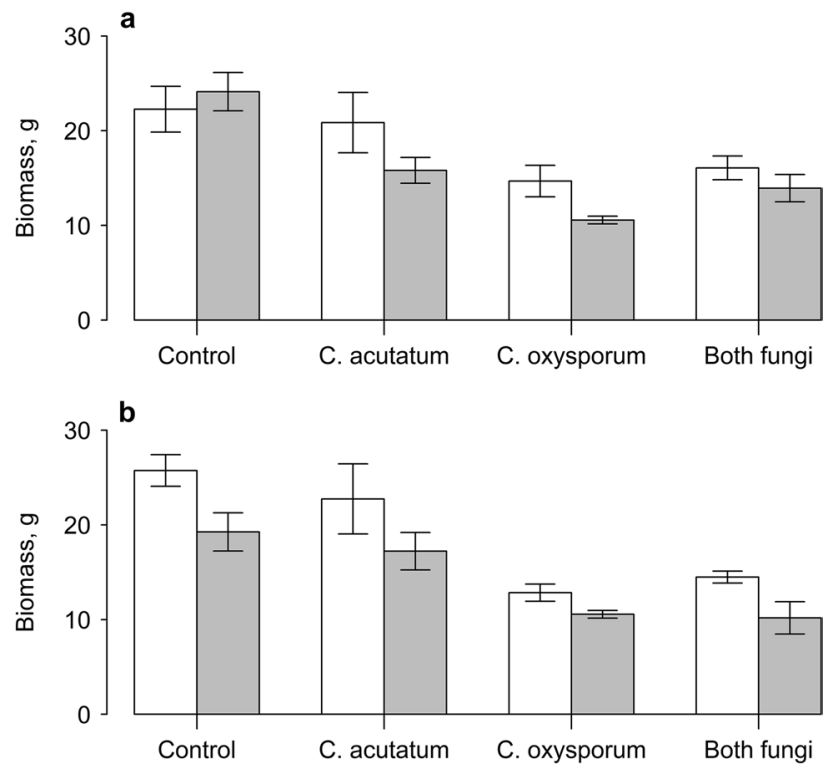

Fig. 2 Fresh biomass of Himalayan balsam plants grown with addition of PlantWorks mycorrhizal inoculum (a) or Symbio mycorrhizal inoculum (b). White bars indicate sterilised inoculum, grey bars indicate live mycorrhizal fungi. Plants were also inoculated with no endophytes (control), C. acutatum, C. oxysporum or both endophyte fungi. Vertical bars represent \pm one standard error

\section{Insect Abundance}

Overall, addition of PlantWorks inoculum resulted in higher numbers of $A$. fabae per plant (main effect: $z=11.8, \mathrm{df}=1$, $P<0.01$ ), but this only occurred when $C$. oxysporum was also inoculated, leading to a significant interaction term between AMF and this endophyte $(z=9.4, \mathrm{df}=1, P<0.01$, Fig. 3a). Highest aphid numbers were found on plants inoculated with mycorrhizal fungi and both endophytes (Fig. 3a). Addition of Symbio inoculum had no effect overall, but appeared to reduce $A$. fabae numbers if no endophyte was applied, leading to a significant interaction term between the AMF, $C$. acutatum and $C$. oxysporum $(z=5.6, \mathrm{df}=1$, $P<0.05$, Fig. 3b). The response of M. ornatus was quite different; addition of PlantWorks inoculum only increased aphid numbers if no endophyte was present, and there was no effect of AMF overall. Meanwhile, inoculation with both $C$. acutatum and $C$. oxysporum increased the numbers of aphids per plant (main effects: $z=8.5$, and $\mathrm{z}=7.8$ respectively, $\mathrm{df}=1, P<0.01$, Fig. $3 \mathrm{c}$ ). There was also an interaction between $\mathrm{AMF}$ and $C$. oxysporum, as the increase in aphids after inoculation with this endophyte only occurred when the mycorrhiza was absent $(z=6.5, \mathrm{df}=1, P<0.05$, Fig. 3c). A similar trend was seen with $C$. acutatum, but the interaction term was not significant. Meanwhile, with Symbio inoculum, no effect of mycorrhizal or endophyte inoculation was found, and there were no interactions between the fungi (Fig. 3d, Tables 1 and 2).

\section{Fungal Colonization and Infection Levels}

No mycorrhizal colonisation was found in any of the PlantWorks or Symbio inoculum control plants. Infection of plants with $C$. acutatum significantly reduced the level of root colonisation by PlantWorks inoculum (main effect: $F_{1,16}=18.13, P<0.001$, Fig. 4 a); however, this only occurred when $C$. oxysporum was not inoculated, leading to a strong interaction between the endophytes $\left(F_{1,16}=23.54\right.$, $P<0.001)$. Overall, colonisation levels resulting from addition of the Symbio inoculum were much lower (Fig. 4b) and these were reduced by inoculation with $C$. oxysporum (main effect: $F_{1,16}=13.08, P<0.01$ ), with no interactions between the endophytes.

Some background levels of infection by $C$. acutatum and C. oxysporum were found in the control plants, but importantly, the isolation frequencies of both endophytes were significantly higher in plants to which the respective fungi were applied (Fig. 5). Addition of PlantWorks inoculum halved the isolation frequency of $C$. acutatum from an overall value of $43 \%$ when AMF were absent, down to $21 \%$ when they were present (main effect: $\chi^{2}=4.6, P<0.05$, Fig. 5a). Inoculation with $C$. oxysporum tended to increase the isolation frequency of $C$. acutatum from an overall value of $25 \%$ up to $39 \%$, but this effect was weak (main effect: $\chi^{2}=3.05$, $P=0.09$, Fig. 5a). Levels of infection by $C$. acutatum were lower with the Symbio inoculum and the reverse effect of mycorrhizal addition was seen, wherein the addition of AMF tended to increase infection of C. acutatum (Fig. 5b). 
Fig. 3 Total numbers of Aphis fabae on plants with (grey bars) and without (white bars) live mycorrhizal fungi addition of PlantWorks inoculum (a) and Symbio inoculum (b) and of Myzus ornatus with PlantWorks (c) and Symbio (d) inocula. Plants were also inoculated with no endophytes (C), C. acutatum (C.a.), C. oxysporum (C.o.) or both endophyte fungi. Vertical bars represent \pm one standard error
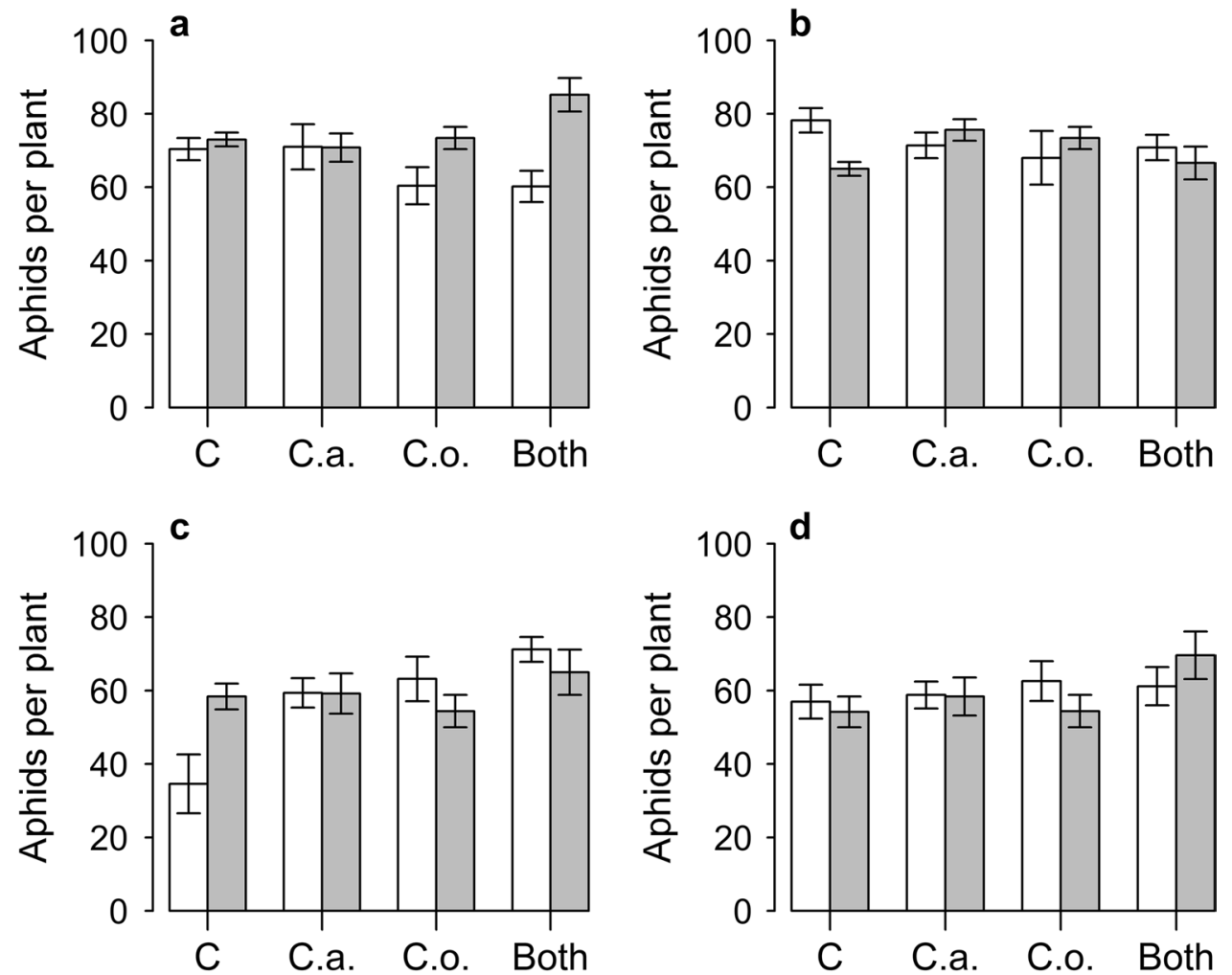

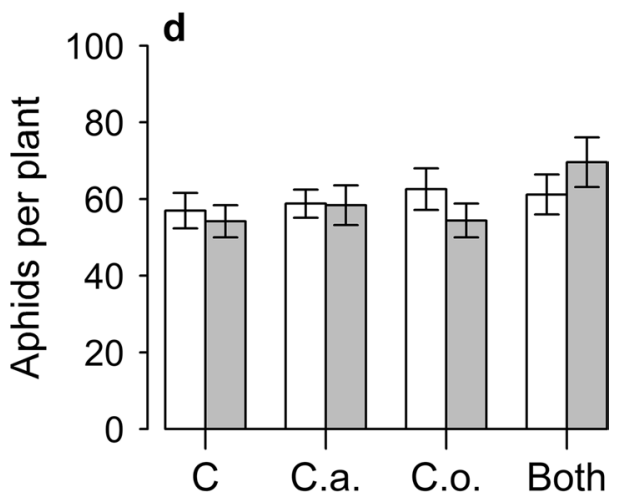

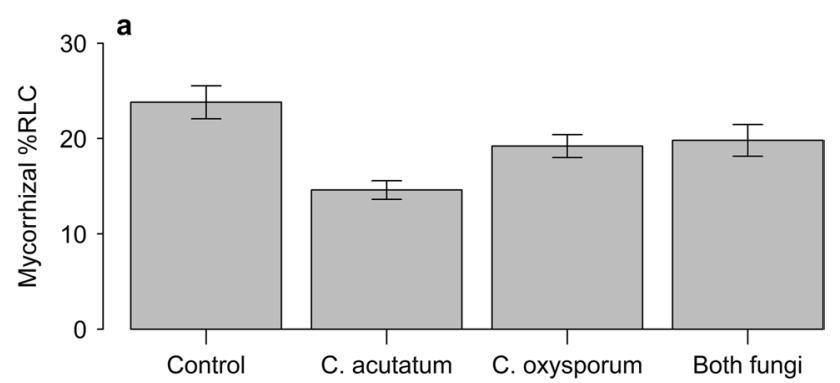

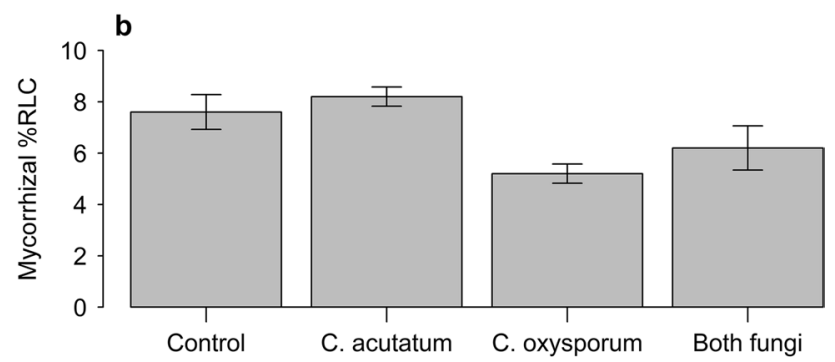

Fig. 4 Percent root length colonised by arbuscular mycorrhizal fungi with the addition of live PlantWorks inoculum (a) or Symbio inoculum (b). Plants were also inoculated with no endophytes (control), $C$. acutatum, C. oxysporum or both endophyte fungi. Vertical bars represent \pm one standard error

However, inoculation of $C$. acutatum resulted in much higher levels of infection by this endophyte when mycorrhizas were present, compared to when they were absent, leading to a significant interaction term $\left(\chi^{2}=4.5, P<0.05\right.$,
Fig. 5b). A further interaction was found between AMF and C. oxysporum, as the highest isolation frequency of $C$. acutatum was found when mycorrhizal fungi were added, but $C$. oxysporum was not $\left(\chi^{2}=8.9, P<0.01\right.$, Fig. $\left.5 b\right)$.

In contrast to $C$. acutatum, addition of the PlantWorks inoculum had no overall effect on infection levels of $C$. oxysporum; however, inoculation with this endophyte only increased its isolation frequency when AMF were absent, showing a significant interaction $\left(\chi^{2}=6.1, P<0.05\right.$, Fig. 5c). A similar effect was seen with the Symbio inoculum; inoculation with $C$. oxysporum increased infection levels of this endophyte by $41 \%$ overall when AMF were absent, but by only $9 \%$ when AMF were added $\left(\chi^{2}=4.5, P<0.05\right.$, Fig. $5 d$, Tables 1 and 2).

Ten other species of background endophytes were found in total across the experiment, these were Acremonium strictum, Alternaria tenuissima, Chaetomium cochliodes, Cladosporium cladosporioides, Cl. sphaerospermum, Clonostachys rosea, Geniculosporium spp., Lecanicillium spp., Peniophora spp. and Trichoderma viride. The Lecanicillium spp. and Peniophora spp. were sterile in culture and were identified molecularly, with GenBank accession numbers MH428682 and MH428683 respectively. In general, most plants were infected by a small number of species, with an overall mean of $2.12 \pm 0.15$ per plant. Addition of PlantWorks inoculum had no effect on endophyte species richness, but inoculation with $C$. oxysporum reduced species number per plant from an average of $2.6 \pm 0.19$ when 
Fig. 5 Isolation frequency of $C$. acutatum on plants inoculated with (grey bars) and without (white bars) live mycorrhizal fungi addition of PlantWorks inoculum (a) and Symbio inoculum (b) and of C. oxysporum with PlantWorks (c) and Symbio (d) inocula. Plants were also inoculated with no endophytes (C), C. acutatum (C.a.), C. oxysporum (C.o.) or both endophyte fungi. Vertical bars represent \pm one standard error
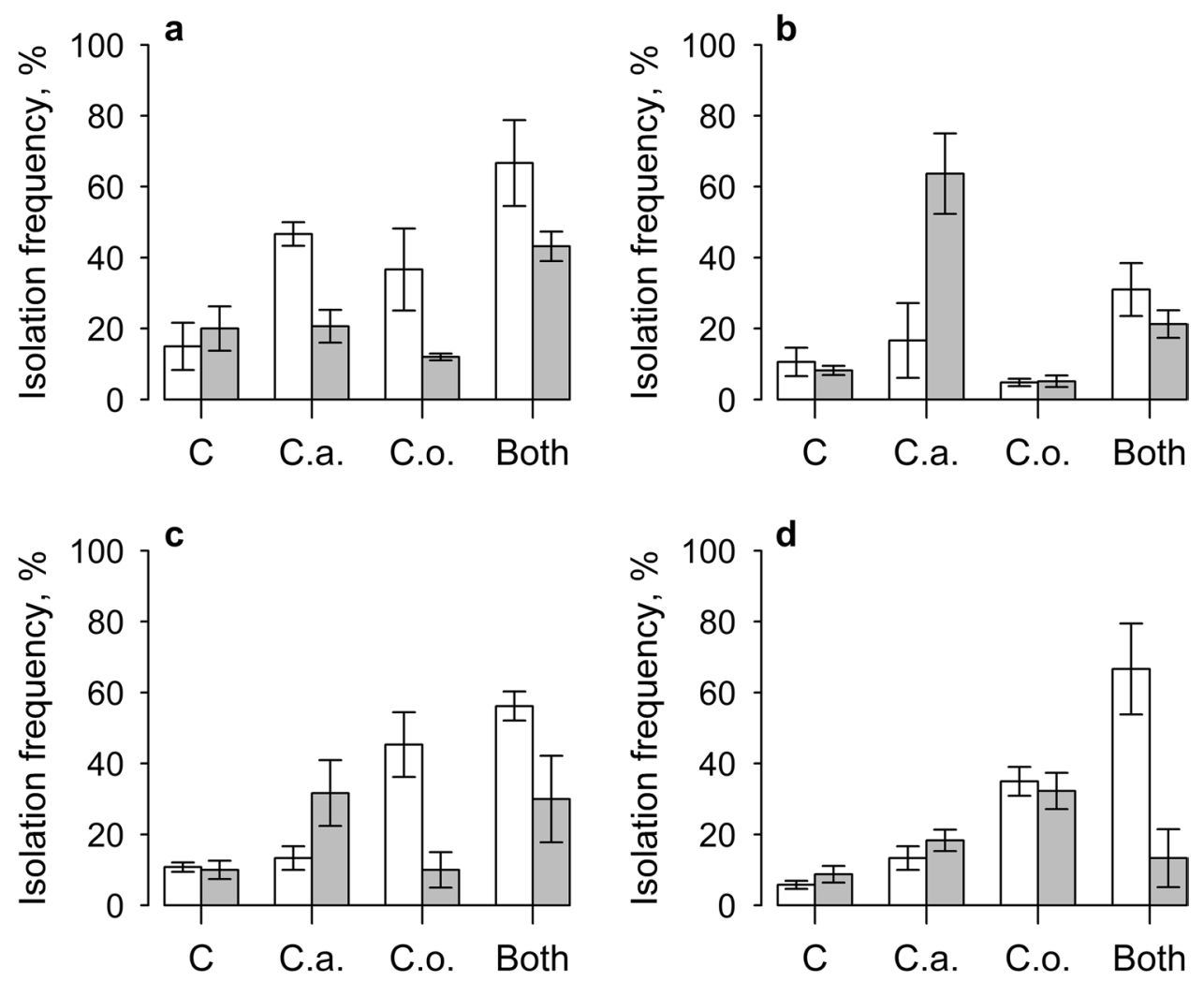

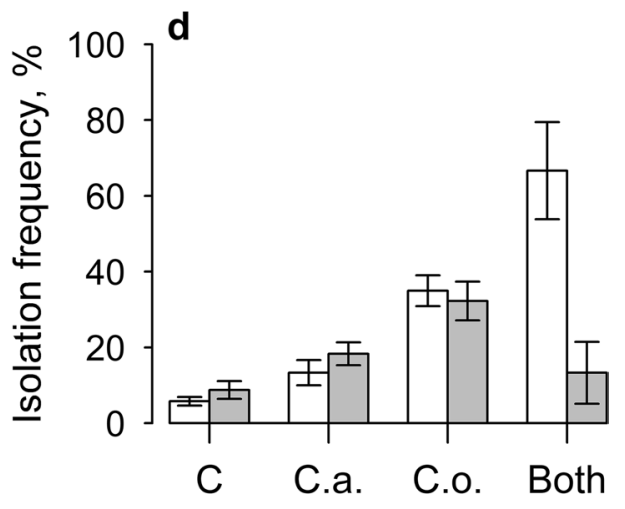

this species was not inoculated to $1.65 \pm 0.18$ when it was (main effect: $z=2.39, P<0.01$ ). Exactly the same effect was found when $C$. oxysporum was inoculated with Symbio $\mathrm{AMF}$; here the endophyte reduced species number per plant from $2.15 \pm 0.18$ down to $1.5 \pm 0.25$ (main effect: $z=2.1$, $P<0.05$ ), while the mycorrhizal fungi had no effect on endophyte species richness.

\section{Discussion}

This is the first study of the interactions between arbuscular mycorrhizal fungi, foliar endophytes, insects and their shared host plant. We found a complex series of interactions, the outcome of which was determined by the identity of the fungi and the insects. Perhaps surprisingly, the majority of the interactions were between the spatially separated AMF and endophytes, suggesting that the mechanism is likely to be one of chemical changes in the host plant, produced and/ or induced by the fungi [45].

Our first hypothesis, that adding AMF would reduce plant growth, was partially upheld, but there was a striking difference between the two inocula. Although colonisation levels resulting from addition of the Symbio inoculum were lower, the reduction in plant biomass was much greater than that resulting from addition of the PlantWorks inoculum. In neither case were the colonisation levels as high as those in natural field populations [31], so the fact that size reductions were found at relatively low colonisation levels is perhaps encouraging for the potential use of the fungi in the biological control of this weed. It is also encouraging in that this result seems to be reproducible; in a previous study, fresh biomass of I. glandulifera was halved when natural mycorrhizal colonisation was doubled [32]. Of the eight explanations for AMF-induced growth depression in plants listed by Jin et al. [25], that of unbalanced carbon-for-nutrient trade seems the most likely here. For an annual plant, I. glandulifera shows a phenomenal growth rate in the invaded range, growing up to $4 \mathrm{~m}$ tall, suggesting that it has a remarkably efficient root system that is highly effective at extracting soil nutrients [29, 30, 37]. Thus, it probably derives little benefit from nutrients donated by the mycorrhizal fungi, while still transferring carbon to its fungal associates. Furthermore, these results suggest that there is a high degree of ecological specificity in the association of this plant with mycorrhizal fungi [23], with the identity of the fungal species being critical in affecting plant growth. This is in line with previous studies, where differences in the performance of different inocula on the same plant have been attributed to differences in their species composition [46]. The Symbio inoculum contains more species than PlantWorks and only two ( $F$. mosseae and $R$. irregularis) are common to both. If one wanted to single out particular species for in-depth study of their antagonism towards I. glandulifera, then extensive 
molecular analyses would need to be done, to determine how many of the species in the inocula actually colonised the roots, something which is very rarely done [47].

Of course, the whole point of mycorrhizal inocula is to achieve beneficial growth effects in a range of horticultural and agricultural crops and there has been some debate as to whether single or multiple species inocula are best to achieve this [48, 49]. One must also consider the economics of inoculum production; the more species in a mixture, the more likely it is that colonisation will occur, and growth benefits will be seen in a range of crops, making the product more successful [50]. Nevertheless, these results suggest that the use of Symbio inoculum in the field would be worth trialling, as it may reduce I. glandulifera growth, while at the same time increasing growth of native species that are more dependent on the mycorrhizal associations which are depleted by I. glandulifera [30, 32]. Such an approach could be a novel use of AMF in habitat restoration and could be appealing to inoculum producers [30].

More surprisingly, inoculation of plants with the endophyte $C$. oxysporum reduced both plant height and biomass with the smallest plants being produced when this endophyte and either mycorrhizal inoculum was added. There was no visual evidence of pathogenicity, with no production of leaf lesions when this species or $C$. acutatum was inoculated, similar to previous experiments with this plant [34]. This effect occurred despite this endophyte also reducing mycorrhizal colonisation by both inocula, further suggesting that the identity of fungi in the plant is more important than the amount of mycorrhizal colonisation in the roots. The performance of mycorrhizal inoculants in field conditions is highly variable and is known to be influenced by the nature and properties of soils, other soil organisms, environmental conditions and the timing of inoculation, in addition to the plant and fungal specificity effects described above [51]. Our results suggest that the identity of endophytes within the leaves of plants can also affect the functioning of the mycorrhizal fungi. While the mechanism of interaction between the spatially separated AMF and foliar endophytes is unknown, it is most likely one of metabolite production [52].

Changes in plant chemistry as a result of mycorrhizal colonisation are often detrimental to chewing insects, though sucking insects often benefit from mycorrhizal presence, through improved nutrition [26, 27]. Our second hypothesis was again only partially upheld, in that addition of PlantWorks inoculum led to an increase in numbers of $A$. fabae (but only when $C$. oxysporum was also inoculated) and had no effect on M. ornatus. Meanwhile, addition of Symbio inoculum had no effect on either aphid. The latter result is most encouraging, as it means that use of this inoculum in the field is unlikely to increase the reservoirs of these two crop pests. Mycorrhizal fungi appear to increase the size of the vascular bundle, thereby making aphid feeding more efficient, and leading to increases in growth and fecundity [27]. It is possible that such physiological changes do not occur in this plant or that both aphids are highly proficient in phloem location, enabling them to be unusually polyphagous. It is known that effects of AMF on aphids are most apparent at low soil nutrient levels [53], but our aim in this study was to use a standardised soil that was most similar to the nutrient-rich environments in which I. glandulifera grows, such as riverbanks and woodland edges [37]. Contrary to expectation, there were notable effects of endophyte inoculation, with both $C$. acutatum and $C$. oxysporum increasing aphid numbers. Our third hypothesis, that endophytes would mitigate any positive mycorrhizal effects, was certainly not upheld. If anything, endophytes tended to act with the mycorrhizal inocula to increase aphid numbers, not reduce them. It is unclear why the endophytes increased numbers of both aphids, when most previous studies have found negative effects of endophyte presence, thought to be caused by induced metabolites being carried in the phloem food supply of the aphids [17]. This is clearly an avenue for further study.

However, close inspection of the aphid data may reveal more subtle effects of the constitution of the mycorrhizal inoculum. One would expect similar effects of the endophytes on the aphids in the absence of either live mycorrhizal inoculum; however, this was not the case. For M. ornatus in particular, inoculation with either endophyte increased aphid numbers on plants receiving sterilised PlantWorks inoculum, but this was not the case with the Symbio inoculum. The only differences between these treatments were the composition of the non-mycorrhizal microbial community added to each and the nature of the carrier material. Both are equally likely [54] but show that our use of two controls was appropriate and that one needs to be very careful when interpreting the results of mycorrhizal addition experiments using different inoculants.

Our third hypothesis was that there would be significant interactions between the endophytes themselves and again, there was little evidence from the inoculations to support this suggestion (though see below regarding the background endophytes). In fact, the majority of significant interactions found were between the endophytes and the mycorrhizal fungi, some of which were quite complex. Addition of PlantWorks inoculum considerably reduced the infection levels of C. acutatum when this endophyte was inoculated, but addition of Symbio inoculum tended to have the opposite effect. Similarly, when plants were inoculated with $C$. oxysporum, isolation frequencies showed the biggest increases when the AMF were absent. A frequent criticism of endophyte inoculation experiments has been the failure to recover the fungi that were inoculated, even though significant effects of inoculation were found on insects or plant growth [17, $55,56]$. Our data suggest that mycorrhizal fungi play an 
important role in endophyte colonisation of their hosts, and need to be controlled for, particularly in field experiments.

AMF are known to alter the structure of foliar endophyte communities in forbs (though not necessarily the species richness of fungi) [57]. In the present study, no effect of mycorrhizal colonisation on the background community of endophytes was seen. This assemblage, as in previous work, was quite species-poor, compared with other forbs $[13,19,32,34]$. However, there was a consistent effect of C. oxysporum in reducing endophyte species richness, thus suggesting that there were some antagonistic effects between endophytes, as we had hypothesised. In a previous metaanalysis involving endophytes and insects, $98 \%$ of studies did not consider the consequences of endophyte inoculation on the background community of fungi [17], yet the interactions with and effects on this community could be just as important as the inoculated fungi themselves [58]. These interactions are likely to involve the production of anti-fungal and anti-insecticidal metabolites by the various endophytes, which could have dramatic effects on the plant and associated insects $[59,60]$.

There is much scope for the use of arbuscular mycorrhizal fungi and endophytes in biological control programmes of weeds, either through direct effects on the weed, or indirect effects through the manipulation of plant competition or insect herbivores [28, 61, 62]. Many endophytes, including the two species used here, are pathogens of other plants and the schizotrophic lifestyle seems to be common amongst endophytes in forbs $[13,14]$. As long as appropriate species of mycorrhizal fungi and strains of endophytes (non-pathogenic to crops) areselected, so that weeds do not become reservoirs of insect pests or crop pathogens, then this represents a promising avenue for future biological control programmes. However, many more multitrophic experiments of the type reported here will be needed, to unravel the complex interactions that exist between the different parts of the plant microbiome.

Acknowledgements We are grateful to Drs Amanda Currie and Neil Morley for technical assistance and Thelma Caine, Dr Alan Buddie and the late Dr Carol Ellison at CABI for assistance with the molecular work and the propagation of Himalayan balsam. We also thank Dr Brian Sutton (ex-CABI) for identification of fungal species and Sue Broughton for comments on the manuscript.

Author contribution ACG and NAR designed the study, which was executed by NAR. Both authors contributed to the analysis and writing of the manuscript.

Funding This study was funded by the Natural Environment Research Council (grant NE/N00244X/1) and Majlis Amanah Rakyat (MARA), Malaysia.

Data availability The datasets generated during and/or analysed during the current study are available from the corresponding author on reasonable request.

\section{Declarations}

Conflict of interest The authors declare no competing interests.

Open Access This article is licensed under a Creative Commons Attribution 4.0 International License, which permits use, sharing, adaptation, distribution and reproduction in any medium or format, as long as you give appropriate credit to the original author(s) and the source, provide a link to the Creative Commons licence, and indicate if changes were made. The images or other third party material in this article are included in the article's Creative Commons licence, unless indicated otherwise in a credit line to the material. If material is not included in the article's Creative Commons licence and your intended use is not permitted by statutory regulation or exceeds the permitted use, you will need to obtain permission directly from the copyright holder. To view a copy of this licence, visit http://creativecommons.org/licenses/by/4.0/.

\section{References}

1. Wilson D (1993) Fungal endophytes - out of sight but should not be out of mind. Oikos 68:379-384. https://doi.org/10.2307/35448 56

2. Hardoim PR, van Overbeek LS, Berg G, Pirttila AM, Compant S, Campisano A, Doering M, Sessitsch A (2015) The hidden world within plants: ecological and evolutionary considerations for defining functioning of microbial endophytes. Microbiol Mol Biol Rev 79:293-320. https://doi.org/10.1128/mmbr.00050-14

3. Fitzpatrick CR, Salas-Gonzalez I, Conway JM, Finkel OM, Gilbert S, Russ D, Teixeira P, Dangl JL (2020) The plant microbiome: from ecology to reductionism and beyond. Ann Rev Microbiol 74:81-100. https://doi.org/10.1146/annur ev-micro-022620-014327

4. Hartley SE, Gange AC (2009) Impacts of plant symbiotic fungi on insect herbivores: mutualism in a multitrophic context. Ann Rev Ent 54:323-342. https://doi.org/10.1146/annurev.ento.54.110807. 090614

5. Vandegrift R, Roy BA, Pfeifer-Meister L, Johnson BR, Bridgham SD (2015) The herbaceous landlord: integrating the effects of symbiont consortia within a single host. PeerJ 3:e1379. https:// doi.org/10.7717/peerj.1379

6. Mack KML, Rudgers JA (2008) Balancing multiple mutualists: asymmetric interactions among plants, arbuscular mycorrhizal fungi, and fungal endophytes. Oikos 117:310-320. https://doi. org/10.1111/j.2007.0030-1299.15973.x

7. Omacini M, Eggers T, Bonkowski M, Gange AC, Jones TH (2006) Leaf endophytes affect mycorrhizal status and growth of coinfected and neighbouring plants. Func Ecol 20:226-232. https:// doi.org/10.1111/j.1365-2435.2006.01099.x

8. Larimer AL, Bever JD, Clay K (2010) The interactive effects of plant microbial symbionts: a review and meta-analysis. Symbiosis 51:139-148. https://doi.org/10.1007/s13199-010-0083-1

9. Liu H, Wu M, Liu JM, Qu YB, Gao YB, Ren AZ (2020) Tripartite interactions between endophytic fungi, arbuscular mycorrhizal fungi, and Leymus chinensis. Microb Ecol 79:98-109. https://doi. org/10.1007/s00248-019-01394-8

10. Vicari M, Hatcher PE, Ayres PG (2002) Combined effect of foliar and mycorrhizal endophytes on an insect herbivore. Ecology 83:2452-2464. https://doi.org/10.2307/3071806

11. Tawaraya K (2003) Arbuscular mycorrhizal dependency of different plant species and cultivars. Soil Sci Plant Nutr 49:655-668. https://doi.org/10.1080/00380768.2003.10410323 
12. Rodriguez RJ, White JF, Arnold AE, Redman RS (2009) Fungal endophytes: diversity and functional roles. New Phytol 182:314 330. https://doi.org/10.1111/j.1469-8137.2009.02773.x

13. Currie AF, Wearn JA, Hodgson S, Wendt H, Broughton SJ, Jin L (2014) Foliar fungal endophytes in herbaceous plants: a marriage of convenience? In: Verma VC, Gange AC (eds) Advances in Endophytic Research, Springer, New Delhi, pp 61-81. https:// doi.org/10.1007/978-81-322-1575-2_3

14. Tian BN, Xie JT, Fu YP, Cheng JS, Li B, Chen T, Zhao Y, Gao ZX, Yang PY, Barbetti MJ et al (2020) A cosmopolitan fungal pathogen of dicots adopts an endophytic lifestyle on cereal crops and protects them from major fungal diseases. ISME J 14:3120 3135. https://doi.org/10.1038/s41396-020-00744-6

15. Gange AC, Currie AF, Spong J-R (2019) Endophytes as novel pest control agents: myth or reality? In: Schouten A (ed) Endophyte Biotechnology, CABI, Wallingford, UK, pp 66-84. https://doi.org/ 10.1079/9781786399427.0068

16. Yan JF, Broughton SJ, Yang SL, Gange AC (2015) Do endophytic fungi grow through their hosts systemically? Fung Ecol 13:53-59. https://doi.org/10.1016/j.funeco.2014.07.005

17. Gange AC, Koricheva J, Currie AF, Jaber LR, Vidal S (2019) Meta-analysis of the role of entomopathogenic and unspecialized fungal endophytes as plant bodyguards. New Phytol 223:20022010. https://doi.org/10.1111/nph.15859

18. Busby PE, Ridout M, Newcombe G (2016) Fungal endophytes: modifiers of plant disease. Plant Mol Biol 90:645-655. https://doi. org/10.1007/s11103-015-0412-0

19. Wearn JA, Sutton BC, Morley NJ, Gange AC (2012) Species and organ specificity of fungal endophytes in herbaceous grassland plants. J Ecol 100:1085-1092. https://doi.org/10.1111/j.13652745.2012.01997.x

20. Wezowicz K, Rozpadek P, Turnau K (2017) Interactions of arbuscular mycorrhizal and endophytic fungi improve seedling survival and growth in post-mining waste. Mycorrhiza 27:499-511. https:// doi.org/10.1007/s00572-017-0768-x

21. Wazny R, Rozpadek P, Jedrzejczyk RJ, Sliwa M, Stojakowska A, Anielska T, Turnau K (2018) Does co-inoculation of Lactuca serriola with endophytic and arbuscular mycorrhizal fungi improve plant growth in a polluted environment? Mycorrhiza 28:235-246. https://doi.org/10.1007/s00572-018-0819-y

22. Delavaux CS, Smith-Ramesh LM, Kuebbing SE (2017) Beyond nutrients: a meta-analysis of the diverse effects of arbuscular mycorrhizal fungi on plants and soils. Ecology 98:2111-2119. https:// doi.org/10.1002/ecy.1892

23. McGonigle TP, Fitter AH (1990) Ecological specificity of vesicular arbuscular mycorrhizal associations. Mycol Res 94:120-122. https://doi.org/10.1016/s0953-7562(09)81272-0

24. Hoeksema JD, Chaudhary VB, Gehring CA, Johnson NC, Karst J, Koide RT, Pringle A, Zabinski C, Bever JD, Moore JC et al (2010) A meta-analysis of context-dependency in plant response to inoculation with mycorrhizal fungi. Ecol Lett 13:394-407. https://doi. org/10.1111/j.1461-0248.2009.01430.x

25. Jin L, Wang Q, Wang Q, Wang XJ, Gange AC (2017) Mycorrhizal-induced growth depression in plants. Symbiosis 72:81-88. https://doi.org/10.1007/s13199-016-0444-5

26. Koricheva J, Gange AC, Jones T (2009) Effects of mycorrhizal fungi on insect herbivores: a meta-analysis. Ecology 90:20882097. https://doi.org/10.1890/08-1555.1

27. Simon AL, Wellham PAD, Aradottir GI, Gange AC (2017) Unravelling mycorrhiza-induced wheat susceptibility to the English grain aphid Sitobion avenae. Sci Rep 7:46497. https://doi.org/10. 1038/srep46497

28. Veiga RSL, Jansa J, Frossard E, van der Heijden MGA (2011) Can arbuscular mycorrhizal fungi reduce the growth of agricultural weeds? PLoS ONE 6: https://doi.org/10.1371/journal.pone.00278 25
29. Coakely S, Petti C (2021) Impacts of the invasive Impatiens glandulifera: lessons learned from one of Europe's top invasive species. Biology 10:619. https://doi.org/10.3390/biology 10070619

30. Tanner RA, Gange AC (2013) The impact of two non-native plant species on native flora performance: potential implications for habitat restoration. Plant Ecol 214:423-432. https://doi.org/10. 1007/s11258-013-0179-9

31. Tanner RA, Jin L, Shaw R, Murphy ST, Gange AC (2014) An ecological comparison of Impatiens glandulifera Royle in the native and introduced range. Plant Ecol 215:833-843. https://doi.org/10. 1007/s11258-014-0335-x

32. Pattison Z, Rumble H, Tanner RA, Jin L, Gange AC (2016) Positive plant-soil feedbacks of the invasive Impatiens glandulifera and their effects on above-ground microbial communities. Weed Res 56:198-207. https://doi.org/10.1111/wre.12200

33. Ellison CA, Pollard KM, Varia S (2020) Potential of a coevolved rust fungus for the management of Himalayan balsam in the British Isles: first field releases. Weed Res 60:37-49. https://doi.org/ 10.1111/wre. 12403

34. Currie AF, Gange AC, Ab Razak N, Ellison CA, Maczey N, Wood SV (2020) Endophytic fungi in the invasive weed Impatiens glandulifera: a barrier to classical biological control? Weed Res 60:50-59. https://doi.org/10.1111/wre.12396

35. Pollard KM, Varia S, Seier MK, Ellison CA (2021) Battling the biotypes of balsam: the biological control of Impatiens glandulifera using the rust fungus Puccinia komarovii var. glanduliferae in GB. Fung Biol 125:637-645. https://doi.org/10.1016/j.funbio. 2021.03.005

36. Bennett $\mathrm{AE}$ (2013) Can plant-microbe-insect interactions enhance or inhibit the spread of invasive species? Func Ecol 27:661-671. https://doi.org/10.1111/1365-2435.12099

37. Tanner RA, Gange AC (2020) Himalayan balsam, Impatiens glandulifera: its ecology, invasion and management. Weed Res 60:4-7. https://doi.org/10.1111/wre.12401

38. Ab Razak N (2019) Interactions between symbiotic and pathogenic fungi in the invasive weed, Impatiens glandulifera (Himalayan balsam). Dissertation, Royal Holloway University of London

39. Koide RT, Li M (1989) Appropriate controls for vesicular-arbuscular mycorrhiza research. New Phytol 111:35-44. https://doi.org/ 10.1111/j.1469-8137.1989.tb04215.x

40. Johnson D, Leake JR, Read DJ (2001) Novel in-growth core system enables functional studies of grassland mycorrhizal mycelial networks. New Phytol 152:555-562. https://doi.org/10.1046/j. 0028-646X.2001.00273.X

41. Vierheilig H, Coughlan AP, Wyss U, Piche Y (1998) Ink and vinegar, a simple staining technique for arbuscular-mycorrhizal fungi. Appl Env Microbiol 64:5004-5007. https://doi.org/10.1128/AEM. 64.12.5004-5007.1998

42. McGonigle TP, Miller MH, Evans DG, Fairchild GL, Swan JA (1990) A new method which gives an objective measure of colonization of roots by vesicular-arbuscular mycorrhizal fungi. New Phytol 115:495-501. https://doi.org/10.1111/j.1469-8137.1990. tb00476.x

43. Warton DI, Hui FKC (2011) The arcsine is asinine: the analysis of proportions in ecology. Ecology 92:3-10. https://doi.org/10.1890/ $10-0340.1$

44. R Core Team (2019) R: a language and environment for statistical computing. R Foundation for Statistical Computing, Vienna

45. Vandana UK, Rajkumari J, Singha LP, Satish L, Alavilli H, Sudheer P, Chauhan S, Ratnala R, Satturu V, Mazumder PB et al (2021) The endophytic microbiome as a hotspot of synergistic interactions, with prospects of plant growth promotion. Biology 10:101. https://doi.org/10.3390/biology10020101

46. Kellogg JA, Reganold JP, Murphy KM, Carpenter-Boggs LA (2021) A plant-fungus bioassay supports the classification of Quinoa (Chenopodium quinoa Willd.) as inconsistently 
mycorrhizal. Microb Ecol 82:135-144. https://doi.org/10.1007/ s00248-021-01710-1

47. Boyer LR, Brain P, Xu XM, Jeffries P (2015) Inoculation of drought-stressed strawberry with a mixed inoculum of two arbuscular mycorrhizal fungi: effects on population dynamics of fungal species in roots and consequential plant tolerance to water deficiency. Mycorrhiza 25:215-227. https://doi.org/10.1007/ s00572-014-0603-6

48. Van Geel M, De Beenhouwer M, Lievens B, Honnay O (2016) Crop-specific and single-species mycorrhizal inoculation is the best approach to improve crop growth in controlled environments. Agron Sustain Dev 36: https://doi.org/10.1007/ s13593-016-0373-y

49. Crossay T, Majorel C, Redecker D, Gensous S, Medevielle V, Durrieu G, Cavaloc Y, Amir H (2019) Is a mixture of arbuscular mycorrhizal fungi better for plant growth than single-species inoculants? Mycorrhiza 29:325-339. https://doi.org/10.1007/ s00572-019-00898-y

50. Gupta MM, Abbott LK (2021) Exploring economic assessment of the arbuscular mycorrhizal symbiosis. Symbiosis 83:143-152. https://doi.org/10.1007/s13199-020-00738-0

51. Berruti A, Lumini E, Balestrini R, Bianciotto V (2016) Arbuscular mycorrhizal fungi as natural biofertilizers: let's benefit from past successes. Front Microbiol 6:1559. https://doi.org/10.3389/fmicb. 2015.01559

52. Chagas FO, Pessotti RD, Caraballo-Rodriguez AM, Pupo MT (2018) Chemical signaling involved in plant-microbe interactions. Chem Soc Rev 47:1652-1704. https://doi.org/10.1039/ c7cs00343a

53. Gange AC, Bower E, Brown VK (1999) Positive effects of an arbuscular mycorrhizal fungus on aphid life history traits. Oecologia 120:123-131. https://doi.org/10.1007/s004420050840

54. Gryndler M, Smilauer P, Puschel D, Bukovska P, Hrselova H, Hujslova M, Gryndlerova H, Beskid O, Konvalinkova T, Jansa J (2018) Appropriate nonmycorrhizal controls in arbuscular mycorrhiza research: a microbiome perspective. Mycorrhiza 28:435450. https://doi.org/10.1007/s00572-018-0844-x
55. Jaber LR, Vidal S (2010) Fungal endophyte negative effects on herbivory are enhanced on intact plants and maintained in a subsequent generation. Ecol Ent 35:25-36. https://doi.org/10.1111/j. 1365-2311.2009.01152.x

56. Gange AC, Eschen R, Wearn JA, Thawer A, Sutton BC (2012) Differential effects of foliar endophytic fungi on insect herbivores attacking a herbaceous plant. Oecologia 168:1023-1031. https:// doi.org/10.1007/s00442-011-2151-5

57. Eschen R, Hunt S, Mykura C, Gange AC, Sutton BC (2010) The foliar endophytic fungal community composition in Cirsium arvense is affected by mycorrhizal colonization and soil nutrient content. Fung Biol 114:991-998. https://doi.org/10.1016/j.funbio. 2010.09.009

58. De Silva NI, Brooks S, Lumyong S, Hyde KD (2019) Use of endophytes as biocontrol agents. Fung Biol Rev 33:133-148. https:// doi.org/10.1016/j.fbr.2018.10.001

59. Nisa H, Kamili AN, Nawchoo IA, Shafi S, Shameem N, Bandh SA (2015) Fungal endophytes as prolific source of phytochemicals and other bioactive natural products: a review. Microb Path 82:50-59. https://doi.org/10.1016/j.micpath.2015.04.001

60. Salvatore MM, Andolfi A, Nicoletti R (2021) The genus Cladosporium: a rich source of diverse and bioactive natural compounds. Molecules 26: https://doi.org/10.3390/molecules261339 59

61. David AS, Quiram GL, Sirota JI, Seabloom EW (2016) Quantifying the associations between fungal endophytes and biocontrol-induced herbivory of invasive purple loosestrife (Lythrum salicaria L.). Mycologia 108:625-637. https://doi.org/10.3852/ 15-207

62. Ahmad Y, Ahmad MN, Zia A, Alam SS, Khan RAA, Riaz M (2020) Biocontrol of economically important weed species through endophytic fungi isolated from Parthenium hysterophorus (Family: Asteraceae). Egypt J Biol Pest Cont 30:138. https:// doi.org/10.1186/s41938-020-00339-5 